\title{
Inhibitory effects of tibial nerve stimulation on bladder neurophysiology in rats
}

\author{
Mahipal Choudhary", Ron van Mastrigt and Els van Asselt
}

\author{
${ }^{*}$ Correspondence: \\ m.choudhary@erasmusmc.nl \\ Department of Urology, \\ Sector FURORE, Room \\ EE1630, Erasmus MC, \\ Dr. Molewaterplein 50, \\ 3015 GE Rotterdam, The \\ Netherlands
}

\begin{abstract}
Tibial nerve stimulation (TNS) is a form of peripheral neuromodulation which has been found effective in treating overactive bladder symptoms, with lesser side effects than first line pharmacotherapy. Despite its widespread clinical use, the underlying mechanism of action is not fully understood. Our aim was to study its effect on the bladder neurophysiology and the trigger mechanism of voiding in the overactive detrusor, simulated by acetic acid (AA) instillation. In urethane anaesthetized male Wistar rats, the tibial nerve was stimulated for $30 \mathrm{~min}$ at $5 \mathrm{~Hz}$, pulse width $200 \mu \mathrm{s}$ and amplitude approximately three times the threshold to induce a slight toe movement. The pressure at which a voiding contraction was triggered ( $p_{\text {thres }}$ ) did not change significantly between the pre- and post-TNS measurements in AA induced detrusor overactivity. It was found that TNS significantly reversed the effects of AA irritation by increasing the bladder compliance and the bladder volume at $\mathrm{p}_{\text {thres }}$ as well as suppressed the threshold afferent nerve activity. The slope of the linear relationship between pressure and the afferent activity increased after AA instillation and decreased significantly after stimulation. In addition to its well-known central inhibitory mechanisms, this study has demonstrated that TNS improves bladder storage capacity by delaying the onset of voiding, via an inhibitory effect on the bladder afferent signaling at the peripheral level.

Keywords: Tibial nerve stimulation, Overactive bladder, Neuromodulation, Afferent nerve activity
\end{abstract}

\section{Background}

A voiding reflex is initiated by bladder afferent nerve fibers which run through the major pelvic ganglion via the pelvic nerve to the L4-S3 level of the spinal cord. Bladder efferent fibers originate at the same level, travel via the spinal nerve, synapse in the major pelvic ganglion and innervate the bladder smooth muscle (Pascual et al. 1989; Keast et al. 1989). At the same spinal level the sciatic nerve originates which at the mid-thigh level splits into tibial, peroneal and sural nerves (Brunner et al. 1980). It is generally believed that superseding a threshold of afferent nerve activity triggers efferent firing to the bladder wall i.e. initiates a voiding contraction (van Asselt et al. 1999). In pathological conditions such as detrusor overactivity this afferent-efferent mechanism is disturbed (de Groat 1997). Evidence of this anomaly is the increased sensitivity of afferent fibers, particularly C-fibers, which has been reported to be one of the underlying causes of detrusor overactivity (Steers 2002). The increased sensitivity leads to symptoms like urgency and frequency. One treatment technique is based on stimulation of posterior

(c) 2016 Choudhary et al. This article is distributed under the terms of the Creative Commons Attribution 4.0 International License (http://creativecommons.org/licenses/by/4.0/), which permits unrestricted use, distribution, and reproduction in any medium, provided you give appropriate credit to the original author(s) and the source, provide a link to the Creative Commons license, and indicate if changes were made. 
tibial nerves for 30 min a few times a week for several months (Peters et al. 2013; Govier et al. 2001). Although this technique has been reported to be promising, the underlying mechanism of action is only partially understood (Gaziev et al. 2013).

To explain the inhibitory effect of tibial nerve stimulation on the bladder, most studies have focused on urodynamic parameters. As neuromodulation takes place via the afferent and/or efferent pathways, our aim was to study its effect on the bladder neurophysiology and the trigger mechanism of voiding in a detrusor overactivity rat model.

\section{Results}

No measurements could be done in 4 of the 14 rats due to equipment failure and the absence of bladder contractions. In the remaining 10 rats a few measurements were excluded from the analysis due to movement artifacts, or a high noise level caused by electrodes touching the surrounding tissue. These artefacts were manifested by irregular peaks in the pressure signal. The $\mathrm{p}_{\text {thres }}$ which marks the beginning of a voiding contraction did not vary among the saline, AA and poststimulation measurements (Table 1). Irritation of the bladder with AA induced an increase in the threshold afferent activity, which was significantly reversed in the poststimulation AA measurements. As expected, the threshold volume and bladder compliance were significantly reduced after AA irritation, and were also restored in the poststimulation AA measurements (Table 1). The maximum pressure $\left(\mathrm{p}_{\max }\right)$ just before the HFOs was found comparable between the three groups, whereas the corresponding afferent nerve activity increased on AA instillation and decreased poststimulation. The pressure rise time $\left(t_{0}-t_{1}\right.$, Fig. 1) from the $\mathrm{p}_{\text {thres }}$ to the actual voiding seemed higher in saline measurements, however the difference between the three groups was not statistically significant. The slope of the

Table 1 Statistical comparison of estimated parameters in pre- and post-stimulation measurements

\begin{tabular}{|c|c|c|c|}
\hline & $\begin{array}{l}\text { Prestimulation } \\
\text { saline (I) }\end{array}$ & $\begin{array}{l}\text { Prestimulation } \\
\text { AA (II) }\end{array}$ & $\begin{array}{l}\text { Poststimulation } \\
\text { AA (III) }\end{array}$ \\
\hline \multicolumn{4}{|l|}{ Automatically calculated } \\
\hline Threshold afferent activity $(\mu \mathrm{V})$ & $0.21 \pm 0.02$ & $0.23 \pm 0.04^{\phi}$ & $0.19 \pm 0.01^{*}$ \\
\hline Maximum afferent activity $(\mu \mathrm{V})$ & $0.25 \pm 0.04$ & $0.41 \pm 0.07^{\phi}$ & $0.22 \pm 0.04^{*}$ \\
\hline Threshold pressure, $\mathrm{p}_{\text {thres }}\left(\mathrm{cmH}_{2} \mathrm{O}\right)$ & $5.2 \pm 2.4$ & $4.4 \pm 2.7^{\mathrm{N} . S}$ & $5.4 \pm 2.8^{\mathrm{N} . S}$ \\
\hline Maximum pressure, $\mathrm{p}_{\max }\left(\mathrm{cmH}_{2} \mathrm{O}\right)$ & $34.4 \pm 7.0$ & $32.5 \pm 7.8^{\text {N.S. }}$ & $30.5 \pm 5.2^{\mathrm{N} . S .}$ \\
\hline Pressure rise time (s) & $59.2 \pm 55.9$ & $54.6 \pm 55.1^{\text {N.S. }}$ & $54.6 \pm 47.9^{\text {N.S. }}$ \\
\hline Slope $\left(\mu \mathrm{V} / \mathrm{cmH}_{2} \mathrm{O}\right)$ & $1.6 \pm 1.4$ & $1.9 \pm 1.5^{\phi}$ & $0.7 \pm 0.6^{*}$ \\
\hline Offset $(\mu \mathrm{V})$ & $0.21 \pm 0.03$ & $0.22 \pm 0.04^{\text {N.S }}$ & $0.19 \pm 0.02^{\text {N.S }}$ \\
\hline Volume, $V_{\text {thres }}(\mathrm{mL})$ & $0.84 \pm 0.2$ & $0.53 \pm 0.2^{\phi}$ & $0.76 \pm 0.3^{*}$ \\
\hline Compliance $\left(\mathrm{mL} / \mathrm{cmH}_{2} \mathrm{O}\right)$ & $0.17 \pm 0.03$ & $0.10 \pm 0.07^{\phi}$ & $0.17 \pm 0.06^{*}$ \\
\hline \multicolumn{4}{|l|}{ Manually calculated } \\
\hline Threshold afferent activity $(\mu \mathrm{V})$ & $0.21 \pm 0.02$ & $0.23 \pm 0.04^{\phi}$ & $0.20 \pm 0.21^{*}$ \\
\hline Threshold pressure $\left(\mathrm{cmH}_{2} \mathrm{O}\right)$ & $6.5 \pm 2.9$ & $5.3 \pm 2.3^{\text {N.S. }}$ & $6.7 \pm 2.5^{\mathrm{N} . S}$ \\
\hline Rise time $(s)$ & $53.2 \pm 55.9$ & $48.6 \pm 55.1^{\text {N.S. }}$ & $45.5 \pm 33.9^{\text {N.S. }}$ \\
\hline
\end{tabular}

Mean $\pm S D$ of the estimated parameters in control saline, prestimulation and poststimulation AA measurements, $n=72$ measurements (saline $=18$, prestimulation $A A=27$, and poststimulation $A A=27$ ). The symbols $\phi$ and * represent the statistical significance $(p<0.05)$ between group I vs II and II vs III respectively. N.S. indicates no statistical difference $(p>0.05)$ between the groups 


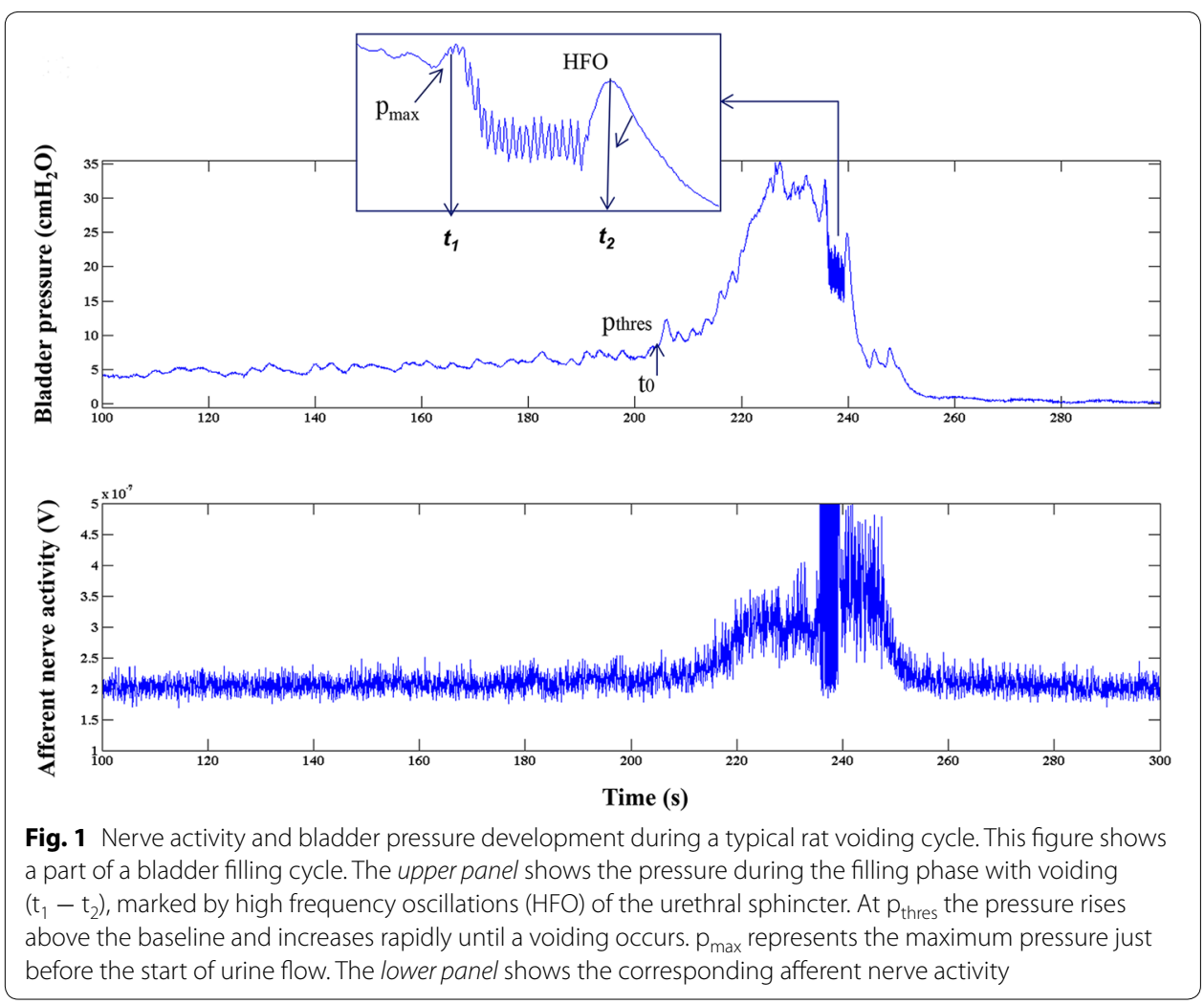

pressure-afferent nerve activity increased on AA instillation and decreased strongly after tibial nerve stimulation. An example of afferent nerve activity as a function of bladder pressure represented by a linear polynomial fit is shown in Fig. 2. The offset which represents nerve activity at pressure $\sim 0$ did not differ between the groups (Table 1 ). To validate the automatic calculation of pressure threshold and afferent activity by the custom written program, we also calculated these parameters by manual identification of the pressure threshold and the corresponding afferent threshold (Table 1). No statistical difference in results between the two methods was observed.

\section{Discussion}

Tibial nerve stimulation is a clinical alternative to pharmacotherapy and has been found effective in restoration of bladder capacity by inhibiting undesired detrusor contractions (Peters et al. 2013; Govier et al. 2001; van Balken et al. 2001). In addition, it has been shown to suppress simulated bladder overactivity in anaesthetized animal models (Tai et al. 2011; Su et al. 2015). To further the understanding of the working mechanism of TNS, we studied its effect on the pressure-afferent nerve activity relationship and the trigger mechanism of voiding.

A voiding reflex is initiated by bladder afferent firing superseding a certain threshold necessary to trigger efferent firing of the bladder nerves (van Asselt et al. 1999). This threshold has been defined as the point where pressure rises above the baseline and increases rapidly until voiding occurs. Although a change was expected during an inhibitory response, in our study, the pressure threshold did not change significantly between 


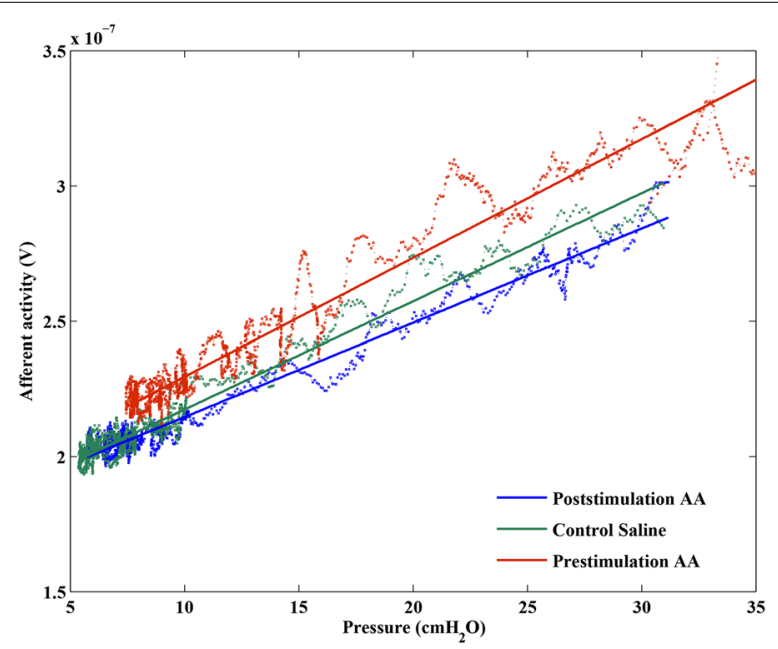

Fig. 2 Example of the effect of tibial nerve stimulation on the slope of the pressure-afferent nerve activity. The slope of afferent nerve activity as a function of bladder pressure was fitted with a straight line representing a linear polynomial fit. Instillation of $0.5 \%$ AA significantly increased the slope of this line in the prestimulation AA measurement (topmost line) as compared to the control saline measurement (middle) and decreased significantly after tibial nerve stimulation (bottom) (3 measurements within 1 animal)

the pre- and post-tibial nerve stimulation measurements. However, the volume threshold was different between both groups after stimulation, implying that the stimulation delayed the onset of voiding to a higher filled volume, without affecting the pressure at this point.

The threshold afferent nerve activity and the slope of the linear pressure-afferent activity relation increased when the bladder was irritated by AA and decreased significantly poststimulation (Fig. 2). The increase in afferent activity can be ascribed to chemical irritation of bladder (Zvara et al. 2010), which causes hypersensitization of nociceptive C-fiber afferents (Tai et al. 2011). Whether the poststimulation decrease is a reversal of the C-fiber sensitization, cannot be ascertained due to the mixed, multifiber nature of our afferent recordings. Though urethane is believed to spare the micturition reflex (Matsuura and Downie 2000), a suppressing effect of anaesthesia on pressure development and/or afferent signaling cannot be ruled out, which however may be expected to affect the pre- and post-stimulation measurements to the same degree.

A peripheral effect of TNS on afferent nerve terminals, to the best of the authors' knowledge, has not been reported elsewhere. It is possible that this effect is caused by a change in bladder compliance. Poststimulation the volume threshold increased while the pressure threshold remained unchanged, implicating an increase in detrusor compliance. It has been shown that pudendal nerve stimulation, via sympathetic efferent pathways, can activate $\beta 3$-adrenoceptors in the detrusor muscle and/or $\alpha$-adrenergic receptors at the vesical ganglia to inhibit detrusor contractions and regulate bladder compliance (McGee et al. 2014; Craggs and McFarlane 1999; Lindstrom et al. 1983; De Groat and Saum 1972). Similar hypotheses have been proposed for the working mechanism of tibial stimulation. According to Matsuta et al. (2014) "TNS might activate a reflex output to the bladder through the sympathetic hypogastric nerves and relax the 
detrusor via $\beta$-adrenergic mechanisms". Further studies on the role of different nerve types in TNS inhibition are warranted for a better understanding.

The role of the central nervous system in neuromodulation has been well established in various studies (Zhang et al. 2015; Xiao et al. 2014; McGee et al. 2014; van der Pal et al. 2006). As the posterior tibial nerve projects to the sacral micturition center and the nucleus of Onuf, the same area where bladder projections are found, it is generally accepted that TNS evokes a central inhibition of micturition pathways and the therapeutic effect of TNS takes place via these areas (Bemelmans et al. 1999; Vandoninck et al. 2003). Recent studies have also suggested the involvement of inhibitory neurotransmitter mechanisms for TNS inhibition of bladder overactivity modulated by activation of $\mu$, $\kappa$ and $\delta$ opioid receptors (Zhang et al. 2015). As evident from the multitude of suggested modes of action, the working mechanism of tibial nerve stimulation is highly complex and occurs at several levels, incorporating a combination of central inhibitory mechanisms as well as an inhibition at the peripheral level, as suggested by our present study.

Although the results presented in this study underline some important basic neurophysiology behind tibial nerve stimulation, the large differences between rats and humans require a careful consideration of the translational aspects. Sensory urgency in humans is a subjective urodynamic diagnosis and cannot be simulated in animal models; therefore the acetic acid irritation model used in this study only mimics one symptom of the human overactive bladder syndrome, the detrusor overactivity.

\section{Conclusions}

We studied the effect of tibial nerve stimulation on the neurophysiology of voiding in terms of the linear relationship between bladder pressure and afferent nerve activity. It was found that 30 min of stimulation favorably affected the slope of this linear relationship, by inhibiting bladder afferent activity and increasing bladder compliance in an anaesthetized rat model of detrusor overactivity. In addition to the established central inhibitory mechanism of TNS, our study provides evidence for an inhibitory effect on afferent signaling at the peripheral level. Additional studies in unanaesthetized animals and the effect of TNS on different neural pathways are warranted for a comprehensive understanding of the neurophysiological mechanism behind TNS.

\section{Methods}

\section{Ethics, consent and permissions}

All laboratory and experimental procedures were conducted in accordance with institutional guidelines of the local Erasmus MC Animal Experiment Committee [Dier Experimenten commissie (DEC)], DEC number: EMC 2092 and 3164, Protocol number: 102-10-06.

\section{Experimental procedures}

A total of 14 male Wistar rats $(432 \pm 45 \mathrm{~g})$ were used in this study. The animals were anesthetized with urethane $(1.2 \mathrm{~g} / \mathrm{kg}$ body weight, intraperitoneally) and placed on a heated undercover. The abdomen was surgically opened and a branch of the postganglionic pelvic nerve (crushed between the major pelvic ganglion and the electrode, so that only afferent nerve signals were recorded) was mounted on a custom made bipolar 
electrode consisting of two thin platinum/iridium hook shaped wires to record afferent nerve traffic. Since we only crushed one branch of the postganglionic pelvic nerve, leaving intact all other branches, this did not have a significant effect on the bladder function (Choudhary et al. 2015). A catheter connected to a disposable pressure transducer and infusion pump was inserted through the apex of the bladder dome. It was used to fill the bladder with saline $(0.06 \mathrm{ml} / \mathrm{min})$ and to record pressure (Statham SP1400 pressure monitor). The tibial nerve was accessed via the medial side of the right hind leg near the ankle. For stimulation a bipolar cuff electrode was placed around the nerve. The abdominal cavity was filled with paraffin oil to prevent the tissue from drying out. At the end of the experiments, the animals were euthanized using intracardiac $\mathrm{KCl}$.

Initially the bladder was filled with physiological saline $(0.9 \% \mathrm{NaCl})$ until voiding occurred and 3-4 micturition cycles were recorded. Next, the bladder was repeatedly filled with $0.5 \%$ Acetic Acid (AA) to induce bladder overactivity. Thereafter the bladder was emptied and the tibial nerve was stimulated for $30 \mathrm{~min}$ with monophasic rectangular pulses of frequency $5 \mathrm{~Hz}$, width $200 \mu$ s and an amplitude approximately 3 times the threshold to induce a slight toe movement. Then, AA infusion was repeated to study the poststimulation effect of TNS.

\section{Signal processing}

Afferent nerve activity was amplified by a DISA 15C01 EMG amplifier (amplification range: 100-200,000) and band-pass filtered with a Krohn-Hite 3944 filter (Bessel, 4th order, $200-2000 \mathrm{~Hz}$ ). Nerve activity and pressure signals were displayed in real-time on a computer screen using a custom written LabVIEW ${ }^{\circledR}$ (National Instruments, USA) program and were sampled and stored at $25 \mathrm{kHz}$ and $25 \mathrm{~Hz}$ respectively. A custom written MATLAB $^{\circledR}$ (Mathworks, USA) program was used to process and analyse the recorded signals. The nerve signal was rectified and averaged by taking the mean of 1000 samples, effectively reducing a $1 \mathrm{~s}$ interval to 25 data samples, similar to the pressure.

The pressure threshold at which a voiding contraction began was determined by another custom written MATLAB ${ }^{\circledR}$ program. The program first smoothed the signal using a Savitzky-Golay filter and then calculated the second derivative of the pressure signal. The pressure at which the second derivative superseded a certain threshold was defined as the pressure threshold $\left(\mathrm{p}_{\text {thres }}\right)$ and the afferent nerve activity at this threshold was calculated. Additionally, we also calculated the filled volume $\left(\mathrm{V}_{\text {thres }}\right)$ and the bladder compliance, $\frac{d V_{\text {thres }}}{d p_{\text {thres }}}$ at the pressure threshold.

The automatically derived pressure threshold and afferent activity were compared to values derived manually at the point where the pressure started to increase rapidly $\left(\mathrm{t}_{0}\right.$, Fig. 1). In rats, voiding is marked by rapid contractions of the urethral sphincter, seen as high frequency oscillations (HFO) in bladder pressure recording. In Fig. 1, $t_{1}$ is the time at the start of HFO and $\mathrm{p}_{\max }$ is the maximum pressure just before the start of HFO.

To compare the relationship between bladder pressure and afferent activity pre- and post-tibial nerve stimulation, a linear regression model was fitted to the afferent activity-pressure data in the interval $t_{0}-t_{1}$ to calculate slope and offset.

All data are presented as mean $\pm \mathrm{SD}$. To compare groups a two-way ANOVA followed by Bonferroni multiple comparison was done using the SPSS $^{\circledR}$ statistical package (version 21.0, SPSS Inc., Chicago, IL, USA). A p $<0.05$ was considered significant. 


\section{Abbreviations}

TNS: tibial nerve stimulation; AA: acetic acid; HFO: high frequency oscillations; $\mathrm{P}_{\max }$ : maximum pressure; $\mathrm{p}_{\text {thres: }}$ : threshold pressure; $V_{\text {thres }}$ : threshold volume.

\section{Authors' contributions}

All authors were responsible for conception and design of the experiments. All authors were responsible for collection, analysis and interpretation of data. MC drafted the manuscript and all authors contributed to the critical revision of the manuscript. All authors read and approved the final manuscript.

\section{Acknowledgements}

Research funded by Marie Curie actions FP7 of European Union, TRUST (training of urology scientists to develop new treatments) programme under Grant 238541.

\section{Competing interests}

The authors declare that they have no competing interests.

Received: 1 October 2015 Accepted: 6 January 2016

Published online: 15 January 2016

\section{References}

Bemelmans BL, Mundy AR, Craggs MD (1999) Neuromodulation by implant for treating lower urinary tract symptoms and dysfunction. Eur Urol 36(2):81-91

Brunner R, Zimmermann P, Klussmann FW (1980) Localization and neurophysiological properties of moto-neurons of the M-triceps surae of the rat after retrograde labeling with Evans blue. Cell Tissue Res 212(1):73-81

Choudhary M, van Asselt E, van Mastrigt R, Clavica F (2015) Neurophysiological modeling of bladder afferent activity in the rat overactive bladder model. J Physiol Sci 65(4):329-338

Craggs M, McFarlane J (1999) Neuromodulation of the lower urinary tract. Exp Physiol 84(1):149-160

de Groat WC (1997) A neurologic basis for the overactive bladder. Urology 50(6A Suppl):36-52 (discussion 53-36)

de Groat WC, Saum WR (1972) Sympathetic inhibition of the urinary bladder and of pelvic ganglionic transmission in the cat. J Physiol 220(2):297-314

Gaziev G, Topazio L, lacovelli V, Asimakopoulos A, Di Santo A, De Nunzio C, Finazzi-Agro E (2013) Percutaneous tibial nerve stimulation (PTNS) efficacy in the treatment of lower urinary tract dysfunctions: a systematic review. BMC Urol 13:61

Govier FE, Litwiller S, Nitti V, Kreder KJ Jr, Rosenblatt P (2001) Percutaneous afferent neuromodulation for the refractory overactive bladder: results of a multicenter study. J Urol 165(4):1193-1198

Keast JR, Booth AM, de Groat WC (1989) Distribution of neurons in the major pelvic ganglion of the rat which supply the bladder, colon or penis. Cell Tissue Res 256(1):105-112

Lindström S, Fall M, Carlsson CA, Erlandson BE (1983) The neurophysiological basis of bladder inhibition in response to intravaginal electrical stimulation. J Urol 129(2):405-410

Matsuta Y, Roppolo JR, de Groat WC, Tai C (2014) Poststimulation inhibition of the micturition reflex induced by tibial nerve stimulation in rats. Physiol Rep 2(1):e00205

Matsuura S, Downie JW (2000) Effect of anesthetics on reflex micturition in the chronic cannula-implanted rat. Neurourol Urodyn 19(1):87-99

McGee MJ, Danziger ZC, Bamford JA, Grill WM (2014) A spinal GABAergic mechanism is necessary for bladder inhibition by pudendal afferent stimulation. Am J Physiol Renal Physiol 307(8):F921-F930

Pascual JI, Insausti R, Gonzalo LM (1989) The pelvic innervation in the rat: different spinal origin and projections in Sprague-Dawley and Wistar rats. Brain Res 480(1-2):397-402

Peters KM, Carrico DJ, Wooldridge LS, Miller CJ, MacDiarmid SA (2013) Percutaneous tibial nerve stimulation for the longterm treatment of overactive bladder: 3-year results of the STEP study. J Urology 189(6):2194-2201

Steers WD (2002) Pathophysiology of overactive bladder and urge urinary incontinence. Rev Urol 4(Suppl 4):S7-S18

Su X, Nickles A, Nelson DE (2015) Differentiation and interaction of tibial versus spinal nerve stimulation for micturition control in the rat. Neurourol Urodyn 34(1):92-97

Tai CF, Chen M, Shen B, Wang JC, Roppolo JR, de Groat WC (2011) Irritation induced bladder overactivity is suppressed by tibial nerve stimulation in cats. J Urology 186(1):326-330

van Asselt E, le Feber J, van Mastrigt R (1999) Threshold for efferent bladder nerve firing in the rat. Am J Physiol $276(6 \mathrm{Pt}$ 2):R1819-R1824

van Balken MR, Vandoninck V, Gisolf KWH, Vergunst H, Kiemeney LALM, Debruyne FMJ, Bemelmans BLH (2001) Posterior tibial nerve stimulation as neuromodulative treatment of lower urinary tract dysfunction. J Urol 166(3):914-918

van der Pal F, Heesakkers JP, Bemelmans BL (2006) Current opinion on the working mechanisms of neuromodulation in the treatment of lower urinary tract dysfunction. Curr Opin Urol 16(4):261-267

Vandoninck V, Van Balken MR, Finazzi Agro E, Petta F, Caltagirone C, Heesakkers JP, Kiemeney LA, Debruyne FM, Bemelmans BL (2003) Posterior tibial nerve stimulation in the treatment of urge incontinence. Neurourol Urodyn 22(1):17-23

Xiao ZY, Reese J, Schwen Z, Shen B, Wang JC, Roppolo JR, de Groat WC, Tai CF (2014) Role of spinal GABA(A) receptors in pudendal inhibition of nociceptive and nonnociceptive bladder reflexes in cats. Am J Physiol Renal 306(7):F781-F789 
Zhang Z, Slater RC, Ferroni MC, Kadow BT, Lyon TD, Shen B, Xiao Z, Wang J, Kang A, Roppolo JR, de Groat WC, Tai C

(2015) Role of $\mu, k$, and $\delta$ opioid receptors in tibial inhibition of bladder overactivity in cats. J Pharmacol Exp Ther 355(2):228-234

Zvara P, Wright AJ, Roach K, Ursiny M, Shapiro B, Dagrosa LM, Nelson MT, Heppner TJ (2010) A non-anesthetized mouse model for recording sensory urinary bladder activity. Front Neurol 1:127

Submit your manuscript to a SpringerOpen ${ }^{\circ}$ journal and benefit from:

- Convenient online submission

- Rigorous peer review

- Immediate publication on acceptance

- Open access: articles freely available online

- High visibility within the field

- Retaining the copyright to your article

Submit your next manuscript at $>$ springeropen.com 